\title{
MODEL BISNIS OLAHAN SINGKONG PADA USAHA PEUYEUM ABBAS SAWARGI KECAMATAN CIMENYAN KABUPATEN BANDUNG
}

\author{
BUSINESS MODEL CANVAS OF PROCESSED CASSAVA ON BUSINESS \\ PEUYEUM ABBAS SAWARGI CIMENYAN DISTRICT BANDUNG REGENCY
}

\section{Dewi Rengganis*, Gema Wibawa Mukti, Yosini Deliana, Dhany Esperanza}

\author{
Program Studi Agribisnis, Fakultas Pertanian, Universitas Padjadjaran \\ *E-mail: dewi_rengganis60@yahoo.com \\ (Diterima 02-05-2018; Disetujui 04-06-2018)
}

\begin{abstract}
ABSTRAK
Penelitian ini bertujuan untuk mengetahui model bisnis pada usaha Peuyeum Abbas Sawargi. Desain penelitian yang digunakan yaitu desain kualitatif dengan teknik studi kasus. Data primer diperoleh dari pemilik dan pengelola Peuyeum Abbass Sawargi. Data dianalisis menggunakan Business Model Canvas. Penggambaran model bisnis didapatkan melalui proses desain bisnis dengan teknik bercerita, berpikir visual, serta prototyping. Hasil penelitian menunjukan terdapat blok bangunan yang merupakan hal utama dalam terbentuknya usaha Peuyeum Abbas Sawargi ini yaitu dengan melihat Key Resources yang telah ada, seperti memanfaatkan singkong yang telah ditanam sehingga dapat dijadikan sebagai peluang bisnisnya. Terdapat beberapa kendala yang terdapat dalam usaha Peuyeum Abbas Sawargi yaitu pada blok Key Activity khususnya pada bagian promosi, pemasaran dan administrasi.
\end{abstract}

Kata kunci: Olahan Singkong, Peuyeum, Model Bisnis Kanvas

\begin{abstract}
This study aims to determine the business model on business Peuyeum Abbas Sawargi. This research is used qualitative design with case study technique. The primary data were obtained from the owner and manager of Peuyeum Abbass Sawargi. Data analysis using Business Model Canvas. The description of business model is obtained through business design process with storytelling technique, visual thinking, and prototyping. The result of the research shows that there is a building block which is the main thing in the formation of Peuyeum Abbas Sawargi business is by looking at Key Resources that already exist, such as using cassava that has been planted so that it can be used as business opportunity. There are several obstacles in business of Peuyeum Abbas Sawargi on Key Activity block especially in the promotion, marketing and administration.
\end{abstract}

Keywords: Processed Cassava, Peuyeum, Business Model Canvas

\section{PENDAHULUAN}

Pertanian merupakan salah satu sektor yang memberikan kontribusi tinggi terhadap pendapatan negara, hal tersebut dapat dilihat melalui pembentukan
Produk Domestik Bruto (di luar perikanan dan kehutanan) pada tahun 2014, yaitu sekitar 879,23 triliun rupiah atau $10,26 \%$ dengan pertumbuhan sekitar 3,90\% dari PDB Nasional (Kementan RI, 


\section{MODEL BISNIS OLAHAN SINGKONG PADA USAHA PEUYEUM ABBAS SAWARGI \\ KECAMATAN CIMENYAN KABUPATEN BANDUNG \\ Dewi Rengganis, Gema Wibawa Mukti, Yosini Deliana, Dhany Esperanza}

2014). Sektor pertanian terdiri atas beberapa subsektor diantaranya, subsektor tanaman pangan, perkebunan, kehutanan, peternakan, dan perikanan (Pusdatin, 2013). Tanaman pangan merupakan subsektor pertanian yang menjadi kebutuhan mendasar bagi penduduk Indonesia, sehingga subsektor pertanian tanaman pangan memiliki peranan yang sangat penting untuk dikembangkan (Chairil, 1999).

Komoditas tanaman pangan yang memiliki peranan penting bagi masyarakat Indonesia selain padi yaitu singkong, Indonesia merupakan negara penghasil singkong terbesar keempat dunia setelah Nigeria, Brasil, dan Thailand (FAO, 2016). Kontribusi Indonesia terhadap produksi singkong di dunia dari tahun 2009 hingga tahun 2013 yaitu mencapai $9,17 \%$ atau rata-rata produksi mencapai 23,62 juta ton umbi basah setiap tahunnya (Pusdating, 2015).

Singkong dapat dimanfaatkan menjadi berbagai macam bahan produk olahan dan menjadi salah satu peluang bisnis yang menguntungkan. Singkong dapat diolah menjadi keripik, tape, getuk, manggleng, enye-enye, sermier, alen-alen dan slondok. Dengan melihat hal tersebut, singkong dapat dijadikan suatu peluang untuk melakukan usaha bisnis.
Bisnis merupakan sejumlah total usaha yang meliputi pertanian, produksi, konstruksi, distribusi, transportasi, komunikasi, usaha jasa dan pemerintah, yang bergerak dalam suatu bidang yang dapat membuat dan memasarkan barang atau jasa kepada konsumen (Bukhori Alma, 2011).

Terdapat peluang bisnis yang dapat mempertahankan singkong sebagai bahan baku dalam suatu agroindustri. Agroindustri merupakan suatu industri yang mengolah produk pertanian atau menggunakan produk pertanian sebagai bahan baku utamanya. Salah satu agroindustri yang menggunakan singkong sebagai bahan baku utamanya yaitu agroindustri tape singkong. Dengan mengembangkan usaha tape singkong ini dapat dijadikan sebagai sumber penghasilan sampingan bagi masyarakat setempat. Selain itu, usaha ini juga merupakan salah satu bentuk dalam mempertahankan makanan tradisional yangberasal dari Jawa Barat. ${ }^{1}$

Sentra penghasil peuyeum terbesar di Bandung terletak di Kecamatan Cimenyan, Kabupaten Bandung. ${ }^{2}$ Usaha

\footnotetext{
1 Admin KIP"Manfaat Tape (Peuyeum)" diakses dari http://dkpp.jabarprov.go.id/manfaat-tapepeuyeum" pada tanggal 18 Februari 2018 pukul 19.32

2 Admin KRP"Bioindustri Ubi Kayu", diakses dari http://dkpp.jabarprov.go.id/bioindustri-
} 
tape singkong di Kecamatan Cimenyan merupakan suatu usaha yang sudah berdiri dari generasi ke generasi, dan diwariskan secara turun temurun oleh nenek moyang mereka. ${ }^{3}$

Terdapat empat tempat usaha di daerah Cimenyan yang memproduksi tape secara terus menerus, diantaranya yaitu usaha tape singkong yang dimiliki oleh Pak Dede dengan rata-rata jumlah produksi tape singkong sebesar 600 $\mathrm{kg} /$ hari, usaha tape singkong milik Pak Cacah Suryani dengan rata-rata jumlah produksi $300 \mathrm{~kg} / \mathrm{hari}$, usaha tape singkong milik Pak Tatang Ridwan dengan rata-rata jumlah produksi 400 $\mathrm{kg} / \mathrm{hari}$ dan usaha tape singkong milik Pak Abbas dengan rata-rata jumlah produksi sebesar $1.000 \mathrm{~kg} / \mathrm{hari}$ (Kantor Desa Cimenyan, 2017). Berdasarkan pemaparan tersebut, maka dapat diketahui bahwa produsen tape singkong terbesar di daerah Cimenyan adalah usaha tape milik Bapak Abbas dengan merek Peuyeum Abbas Sawargi.

Peuyeum Abbas Sawargi ini telah memiliki izin usaha dari pemerintah yaitu

ubi-jalar pada tanggal 19 Februari 2018 pukul 21.27

${ }^{3}$ Euis, Lilis "Cimenyan dan Peuyeum", diakses dari http://www.noong.or.id/wpcontent/uploads/2016/12/Noong-

Cimenyan pada tanggal 19 Februari 2018 pukul 22.03
Pangan Industri Rumah Tangga (P-IRT) dari Badan Pengawas Obat dan Makanan (BPOM). Selain merupakan agroindustri peuyeum terbesar di Kecamatan Cimenyan yang telah memiliki izin usaha P-IRT, dalam menjangkau konsumen akhir Peuyeum Abbas Sawargi ini melakukan pemasaran dengan menjual peuyeum tersebut secara langsung yang dilakukan di tempat pengolahan dan secara tidak langsung yaitu bermitra dengan toko kue Kartika Sari dan toko oleh-oleh khas Bandung. ${ }^{4}$

Berdasarkan latar belakang tersebut, terdapat hal yang dapat dikaji seperti mengkaji model bisnis dalam usaha Peuyeum Abbas Sawargi. Adanya hal ini, bertujuan untuk melihat dan menggambarkan model bisnis yang terdapat dalam usaha Peuyeum Abbas Sawargi, dimana usaha Peuyeum Abbas Sawargi ini merupakan industri kecil yang dapat menghasilkan peuyeum berkualitas. Selain itu, produksi dan pendapatannya yang continue membuat usaha peuyeum ini dapat berkembang dari generasi ke generasi dan bertahan dengan baik. Adanya model bisnis tersebut diharapkan dapat menjadi percontohan untuk industri kecil lainnya.

${ }^{4}$ Hasil wawancara dengan Bapak Een sebagai pengelolaPeuyeum Abbas Sawargi pada tanggal 22 Februari 2018 


\section{MODEL BISNIS OLAHAN SINGKONG PADA USAHA PEUYEUM ABBAS SAWARGI \\ KECAMATAN CIMENYAN KABUPATEN BANDUNG \\ Dewi Rengganis, Gema Wibawa Mukti, Yosini Deliana, Dhany Esperanza}

Menurut Osterwalder dan Pigneur (2012), adanya model bisnis di suatu perusahaan dapat membantu dalam meningkatkan laba serta daya saing perusahaan.

Model bisnis juga dapat memberikan manfaat lainnya, seperti dapat membantu perusahaan dalam menemukan tujuan dari suatu bisnis dengan jelas dan memberikan solusi mengenai target apa yang harus dicapai sehingga produk yang dihasilkan dapat menarik perhatian konsumen. Untuk mengetahui model bisnis pada usaha Peuyeum Abbas Sawargi dapat diketahui dengan menggunakan sembilan blok Business Model Canvas (BMC) sehingga akan lebih jelas untuk menentukan langkah perusahaan agar dapat bersaing. Oleh karena itu, dalam penelitian ini akan melihat model bisnis yang digunakan pada usaha Peuyeum Abbas Sawargi dengan menggunakan model bisnis kanvas. Penggunaan model bisnis kanvas dapat memberikan gambaran mengenai model bisnis suatu perusahaan dan hubungan yang terjadi antar blok. Berdasarkan uraian tersebut, penulis tertarik untuk melakukan penelitian mengenai "Model Bisnis Olahan Singkong pada Usaha Peuyeum Abbas Sawargi di Kecamatan Cimenyan, Kabupaten Bandung”.

\section{METODE PENELITIAN}

\section{Desain Penelitian dan Tempat Penelitian}

Penelitian ini merupakan penelitian kualitatif deskriptif yang dilakukan dengan teknik studi kasus yang memfokuskan untuk mengetahui model bisnis olahan singkong pada usaha peuyeum Abbas Sawargi, Kecamatan Cimenyan, Kabupaten Bandung.

Tempat penelitian ini dipilih karena Kecamatan Cimenyan merupakan sentra pembuatan peuyeum di Bandung dan produksi peuyeum terbesar di Kecamatan Cimenyan.

\section{Jenis Data dan Sumber Data}

Jenis data yang dikumpulkan terdiri atas data primer dan data sekunder. Teknik pengumpulan data yang dilakukan adalah: 1) Observasi, yaitu pengamatan langsung yang dilakukan untuk mendapatkan data atau informasi guna mendukung keberlangsungan penelitian, 2) Wawancara, yaitu salah satu teknik pengumpulan data melalui dua orang untuk saling bertukar data/ informasi melalui tanya jawab, 3) Dokumen, merupakan catatan peristiwa berbentuk tulisan maupun gambar. 


\section{Analisis Data}

Data dianalisis menggunakan Business Model Canvas yang menggunakan beberapa teknik desain bisnis. Desain bisnis merupakan teknik yang digunakan sebagai alat bantu untuk menjawab pertanyaan dalam penelitian. Terdapat enam teknik desain bisnis, yaitu: wawasan konsumen, pembentukan ide, berpikir visual, prototyping, bercerita, dan skenario.

\section{HASIL DAN PEMBAHASAN}

\section{Profil Singkat Peuyeum Abbas Sawargi}

Peuyeum Abbas Sawargi merupakan salah satu bentuk usaha yang menjadikan singkong sebagai bahan baku utama dalam industrinya. Peuyeum Abbas Sawargi ini didirikan pada tahun 1970 oleh Bapak Abbas. Beliau telah mendapatkan ilmu dan pengalaman dalam memproduksi tape singkong ini dari orang tuanya. Peuyeum Abbas Sawargi dikelola oleh keluarga secara turun temurun. Tujuan didirikan usaha ini yaitu untuk menambah pendapatan sehingga dapat memenuhi kebutuhan hidup dengan memanfaatkan singkong yang ditanam, singkong tersebut kemudian diolah menjadi peuyeum. Salah satu alasan Bapak Abbas mengolah singkong menjadi peuyeum yaitu dikarenakan pembuatan peuyeum ini tidak memerlukan biaya yang cukup tinggi serta proses pembuatannya pun lebih mudah dari pada mengolah singkong menjadi olahan makanan lainnya. Usaha peuyeum ini telah dilakoni secara turun temurun, seiring dengan berjalannya waktu, usaha peuyeum milik Bapak Abbas ini semakin berkembang, pada tahun 2014 Bapak Abbas mulai mengurus surat perijinan untuk usaha yang didirikannya.

Usaha Peuyeum Abbas Sawargi ini merupakan agroindusrti yang dikelola oleh keluarga. Bapak Abbas merupakan pemilik dari Peuyeum Abbas Sawargi yang bertugas untuk memantau dan memastikan proses produksi usaha peuyeum tersebut berjalan dengan lancar. Terdapat tiga pengelola yang memiliki peran dan tanggungjawab yang berbeda, pengelola Peuyeum Abbas Sawargi ini yaitu Bapak Een, Bapak Aan dan Bapak Ajat. Bapak Een memiliki tugas dan tanggung jawab di bagian administrasi, seperti bertanggung jawab atas pencatatan jumlah penjualan tape singkong, pembelian singkong, pengeluaran biaya lainnya dan melakukan pemesanan singkong. Bapak Aan memiliki tugas dan tanggung jawab dalam melakukan proses produksi, beliau 


\section{MODEL BISNIS OLAHAN SINGKONG PADA USAHA PEUYEUM ABBAS SAWARGI \\ KECAMATAN CIMENYAN KABUPATEN BANDUNG \\ Dewi Rengganis, Gema Wibawa Mukti, Yosini Deliana, Dhany Esperanza}

merupakan penanggungjawab dari kegiatan produksi Peuyeum Abbas Sawargi. Bapak Ajat memiliki peranan dalam usaha ini yaitu bertanggungjawab dalam bidang transportasi seperti mengantarkan pesanan tape singkong ke beberapa toko dan bertugas untuk mengambil bahan baku singkong yang telah dipesan sebelumnya. Selain terdapat pengelola yang membantu dalam menjalankan usaha Peuyeum Abbas Sawargi, terdapat juga pegawai yang dapat melancarkan proses produksi peuyeum ini. Pegawai yang bertugas untuk memproduksi tape singkong didominasi oleh keluarga dan sebagian merupakan warga sekitar yang tinggal berdekatan dengan tempat produksi Peuyeum Abbas Sawargi.

\section{Analisis Business Model Canvas (BMC)}

$$
\text { Business Model Canvas (BMC) }
$$
merupakan metode yang digunakan untuk menggambarkan model bisnis yang digunakan oleh usaha Peuyeum Abbas Sawargi. Model bisnis ini merupakan suatu hubungan antara sumberdaya yang dimiliki oleh perusahaan dengan kegiatan yang akan dilakukan untuk menciptakan suatu nilai, sehingga suatu perusahaan mampu menghasilkan keuntungan. Terdapat sembilan blok dalam model bisnis kanvas yang dideskripsikan melalui teknik desain bisnis yang berbeda-beda. Blok customer segments, value propositions, channels, customer relationships, revenue streams, dan cost structure didapatkan melalui teknik bercerita. Sedangkan pada blok key resources, key activities, dan key partnerships didapatkan melalui teknik berpikir visual. Ketika sembilan blok telah dideskripsikan, maka selanjutnya dilakukan teknik prototyping untuk menggambarkan model bisnis Peuyeum Abbas Sawargi secara menyeluruh.

\section{Segmen Pelanggan (Customer Segments)}

Peuyeum Abbas Sawargi memiliki customer segments yang termasuk ke dalam segmen pasar Mass Market (pasar terbuka) dimana Peuyeum Abbas Sawargi tidak mengelompokkan pelanggan dalam berbagai kelompok atau segmen khusus. Sehingga segmentasi konsumen dari Peuyeum Abbas Sawargi ini yaitu seluruh masyarakat yang berdomisili di Kota dan Kabupaten Bandung serta wisatawan yang datang ke daerah Bandung.

\section{Proposisi Nilai (Value Propositions)}

Menurut Osterwalder dan Pigneur (2010), value propositions merupakan suatu sifat atau manfaat yang ditawarkan 
oleh perusahaan kepada konsumen yang dapat menarik perhatian sehingga dapat beralih dari perusahaan satu ke perusahaan lain. Elemen yang terdapat dalam value propositions ini terdiri atas sifat baru, kinerja, penyesuaian, menyelesaikan pekerjaan, desain, merek, harga, pengurangan resiko, kemampuan dalam mengakses, dan kenyamanan. Value propositions yang terdapat pada usaha peuyeum ini yaitu menjual produk fermentasi singkong yang dicampurkan ragi, dengan merek Peuyeum Abbas Sawargi. Peuyeum ini memiliki kualitas baik dengan harga yang terjangkau.

Selain memproduksi peuyeum, Abbas Sawargi memiliki inovasi baru yaitu membuat keripik yang berbahan dasar dari peuyeum. Keripik peuyeum ini mulai diproduksi pada akhir tahun 2017, karena keripik peuyeum masih baru diproduksi maka, masih sedikit konsumen yang mengetahui produk tersebut dan belum memiliki pasar yang tetap. Pemasaran keripik peuyeum ini belum luas dan baru mencoba untuk memasarkan keripik peuyeum tersebut di toko oleh-oleh yang berada di rest area KM 62 dan KM 97, penjualannya pun belum continue. Keripik peuyeum Abbas Sawargi menyediakan berbagai macam rasa, seperti rasa balado, cabe hijau, coklat dan original.

Pada kemasan peuyeum dan kripik peuyeum Abbas Sawargi telah dicantumkan label halal, nomor P-IRT, informasi nilai gizi, tanggal expired, komposisi, serta jumlah isi pada setiap kemasan. Dengan adanya hal tersebut, diharapkan dapat memberikan informasi sehingga dapat menjadi nilai penting bagi konsumen. Peuyeum Abbas Sawargi ini telah menghasilkan produk yang berkualitas, hal tersebut dapat dilihat dari adanya izin usaha pangan berskala rumah tangga yang telah dikantongi oleh usaha Peuyeum Abbas Sawargi ini yaitu Pangan Industri Rumah Tangga (P-IRT) dari Badan Pengawas Obat dan Makanan (BPOM).

Dengan adanya P-IRT ini, makanan yang dipasarkan telah melewati berbagai tahapan pengujian sehingga makanan tersebut telah dipastikan benar-benar aman untuk dikonsumsi dan tidak diragukan lagi oleh pembeli. Nomber PIRT yang dimiliki oleh Peuyeum Abbas Sawargi ini yaitu P-IRT No. 6153204012445-21 yang telah tertera pada label kemasan. Selain memiliki kualitas yang baik, peuyeum ini memiliki harga yang mudah dijangkau oleh masyarakat. 


\section{MODEL BISNIS OLAHAN SINGKONG PADA USAHA PEUYEUM ABBAS SAWARGI \\ KECAMATAN CIMENYAN KABUPATEN BANDUNG \\ Dewi Rengganis, Gema Wibawa Mukti, Yosini Deliana, Dhany Esperanza}

Kinerja yang diberikan kepada pelanggan dari Peuyeum Abbas Sawargi ini yaitu kualitas produk yang terjamin mulai dari pemilihan bahan baku sampai pengolahannya. Jenis singkong yang digunakan untuk dapat diolah menjadi peuyeum ini yaitu menggunakan singkong mangu dan mentega. Kebersihan tempat produksi dan cara produksi yang dijaga oleh pihak Peuyeum Abbas Sawargi akan mempengaruhi rasa pada peuyeum tersebut.

Selain itu, kinerja yang diberikan pihak Peuyeum Abbas Sawargi yaitu menjaga hubungan dan memberi pelayanan kepada pelanggan dengan ramah dan sopan, hal ini ditujukan kepada setiap konsumen yang ingin memesan Peuyeum Abbas Sawargi baik via telepon ataupun langsung dengan mengunjungi tempat pengolahan, pelayanan lain yang diberikan oleh pihak Peuyeum Abbas Sawargi ini yaitu dengan mengantarkan pesanan peuyeum tersebut ke toko yang telah bermitra dengan Abbas Sawargi dan dilayani dengan baik.

Kemampuan dalam mengakses dimiliki oleh Peuyeum Abbas Sawargi sebagai value propositions yang diberikan kepada konsumen. Hasil produksi akan dikirim langsung kepada konsumen yaitu Toko Kue Kartika Sari,
Toko Oleh-oleh Khas Bandung yang berada di Jln. Pasteur, Jln. Buah Batu, Jln. Kopo dan kios di rest area KM 62 dan KM 97. Adanya jasa antar atau delivery dapat memudahkan konsumen untuk mendapatkan peuyeum Abbas ini, setiap konsumen yang telah memesan peuyeum tersebut dapat diantar ke tempatnya. Peuyeum akan dikirim sesuai dengan kesepakatan maka biasaya toko yang bermitra dengan Peuyeum Abbas Sawargi ini melakukan pememesan terlebih dahulu sekitar 2-3 hari sebelum pengiriman. Alasan adanya pemesanan ini yaitu agar dapat mempersiapkan singkong yang merupakan bahan utama dalam pembuatan peuyeum sehingga sebanyak apapun pesanan akan dapat terpenuhi. Peuyeum Abbas Sawargi mengirim hasil produksi dengan menggunakan mobil pick up, sehingga dapat membawa semua pesanan.

\section{Saluran (Channels)}

Channels merupakan suatu bagian yang harus dimiliki oleh perusahaan, adanya channel di suatu perusahaan dapat membantu dalam menjangkau konsumen sehingga dapat memberikan proporsi nilai (value propositions). Menurut Osterwalder dan Pigneur (2012), bahwa saluran (Channels) terbagi atas 2 jenis 
saluran yaitu indirect channels dan direct channels.

Saluran yang digunakan oleh Peuyeum Abbas Sawargi dalam menjangkau pelanggan yaitu dengan menggunakan saluran indirect channels, dimana konsumen dapat memperoleh peuyeum tersebut tidak hanya secara langsung dari perusahaan, melainkan konsumen dapat mengunjungi took-toko yang telah bermitra saja. Peuyeum Abbas Sawargi melakukan kemitraan dengan beberapa toko oleh-oleh dan toko kue Kartika Sari. Toko oleh-oleh yang biasa dipasok oleh Peuyeum Abbas Sawargi ini adalah toko oleh-oleh khas Bandung yang berada di Jalan Pasteur, Jalan Buah Batu, Jalam Kopo, dan kios di rest area Tol Cipularang KM 62 dan KM 97.

Selain menggunakan saluran indirect channels, Peuyeum Abbas Sawargi dapat menjangkau konsumen dengan menggunakan saluran direct channels atau saluran yang dilakukan secara langsung, dimana konsumen dapat memperoleh Peuyeum Abbas Sawargi ini dengan cara mengunjungi langsung tempat produksi peuyeum ini yang berada di Desa Cimeunyan, Kecamatan Cimeunyan, Kabupaten Bandung.

\section{Hubungan Pelanggan (Customer Relationships)}

Hubungan Pelanggan (Customer Relationships) dalam penelitian ini berfokus pada pola hubungan perusahaan dengan pelanggan, hal tersebut dilihat dari cara perusahaan dalam menciptakan hubungan yang baik dengan pelanggannya. Suatu penghubung yang dapat disediakan oleh perusahaan untuk dapat menjangkau konsumen yaitu dengan adanya saluran komunikasi, distribusi dan penjualan.

Hubungan pelanggan yang terdapat pada usaha Peuyeum Abbas Sawargi ini didorong oleh strategi customer acquisition yaitu mencari pelanggan baru dengan melakukan kegiatan pameran atau Bazar. Dalam melakukan kegiatan pameran atau bazar yang dilakukan oleh Peuyeum Abbas Sawargi ini terbilang tidak sering dilakukan, dikarenakan pihak peuyeum Abbas Sawargi ini melakukan pameran atau bazar apabila kegiatan tersebut dilakukan secara gratis saja. Pameran yang pernah diikuti oleh Puyeum Abbas Sawargi ini yaitu pameran yang diadakan oleh Pemerintah Provinsi Jawa Barat, Dinas Koperasi dan UMKM Provinsi Jawa Barat, dan Dinas Pertanian Kabupaten Bandung seperti pada saat merayakan hari jadi Dinas Pertanian Kabupaten Bandung. 


\section{MODEL BISNIS OLAHAN SINGKONG PADA USAHA PEUYEUM ABBAS SAWARGI \\ KECAMATAN CIMENYAN KABUPATEN BANDUNG \\ Dewi Rengganis, Gema Wibawa Mukti, Yosini Deliana, Dhany Esperanza}

Peuyeum Abbas Sawargi juga melakukan beberapa upaya dalam mempertahankan pelanggan (customer retention) diantaranya yaitu menjaga hubungan baik dengan pelanggan di saat berinteraksi secara langsung ataupun secara tidak langsung. Selain dengan memberikan hubungan yang baik, pihak Peuyeum Abbas Sawargi ini menjaga kepercayaan konsumen seperti dengan menyelesaikan pesanan tepat waktu sesuai perjanjian.

Fungsi upselling pada hubungan pelanggan, Peuyeum Abbas Sawargi bermitra dengan petani singkong di daerah setempat dan di daerah lain seperti Sukabumi, Subang, Padalarang untuk memenuhi permintaan pasar dan antisipasi apabila terjadi penambahan permintaan sehingga Peuyeum Abbas Sawargi dapat memenuhi permintaan tersebut. Dengan adanya mitra, hal ini tentunya dapat memberikan manfaat dan keuntungan satu sama lain. Selain itu, dengan memenuhi permintaan konsumen akan menciptakan hubungan yang baik antara konsumen dengan Peuyeum Abbas Sawargi.

Terdapat beberapa jenis hubungan dengan pelanggan. Hubungan pelanggan yang terjalin pada usaha Peuyeum Abbas Sawargi ini termasuk ke dalam bantuan personal (Personal Assistance) yaitu suatu bentuk komunikasi yang terjadi antara petugas yang dapat memberikan pelayanan dengan pelanggan selama proses penjualan dan pasca pembelian. Dengan adanya komunikasi yang dilayani oleh petugas memberikan kemudahan bagi pelanggan dalam mendapatkan bantuan. Hal terpenting dalam membangun hubungan dengan pelanggan bagi Peuyeum Abbas Sawargi ini yaitu dengan terciptanya sutau kemampuan dalam menyelesaikan pesanan tepat waktu, menjaga kualitas peuyeum dengan memperhatikan jenis singkong yang akan digunakan dan menjaga kebersihan selama proses pembuatan sehingga dapat menciptakan peuyeum yang manis, empuk, legit dan lembut.

Selain itu, dengan memberikan pelayanan yang baik seperti adanya komunikasi yang dijalin antara petugas dengan pelanggan secara langsung apabila terjadi masalah selama proses penjualan atau setelah pembelian selesai. Pihak Peuyeum Abbas Sawargi juga memperbolehkan pengembalian barang (retur) yang dikirim apabila terjadi kerusakan yang amat fatal pada produk yang dijualnya. Seperti besek yang merupakan kemasan dari Peuyeum Abbas Sawargi ini basah dan terdapat label yang 
sobek atau rusak. Kerusakan tersebut terjadi karena tidak adanya Standard Operating Procedures (SOP) dalam produksi Peuyeum Abbas Sawargi sebagai acuan dari kegiatan produksi. Menurut Bapak Een sebagai kepala bagian produksi di Peuyeum Abbas Sawargi, produksi peuyeum ini dilaksanakan sesuai tata cara yang dijelaskan oleh pemilik yaitu Bapak Abbas. Namun pada proses produksi dan pengemasan masih dilakukan secara manual.

\section{Arus Pendapatan (Revenue Streams)}

Menurut Osterwalder dan Pigneur (2012), arus pendapatan dalam BMC ini dapat dibedakan menjadi 2 jenis, yaitu pendapatan yang didapat dari hasil pembayaran pelanggan dalam satu kali pembayaran dan pendapatan yang didapat dari pembayaran yang berulang atau berkelanjutan dengan tujuan untuk memberikan value propositions kepada sutau pelanggan.

Arus pendapatan dalam Peuyeum Abbas Sawargi diperoleh dari asset sale (penjualan aset) atau penjualan produk dan jasa yang ditawarkan. Produk yang ditawarkan oleh perusahaan yaitu berupa hasil fermentasi singkong dengan ragi yang kemudian menghasilkan tape singkong atau peuyeum. Arus pendapatan Peuyeum Abbas Sawargi diperoleh dari transaksi yang dilakukan oleh pembeli melalui uang tunai. Tape singkong atau Peuyeum yang telah dikirim dan dibeli akan langsung dibayar pada saat itu juga. Omzet yang didapat dari penjualan peuyeum ini pada setiap bulannya ratarata sebesar $\mathrm{Rp} 50.000 .000 .00$ - Rp 70.000.000.00.

Peuyeum Abbas Sawargi menyediakan jasa antar dengan tarif yang berbeda-beda. Tarif tersebut disesuaikan dengan jarak dan jumlah peuyeum yang dipesan, tarif terbesar yang pernah ditawarkan oleh pihak Peuyeum Abbas Sawargi yaitu sebesar Rp 50.000,00.,dengan adanya jasa antar ini dapat menambah penghasilan meskipun kegiatan ini jarang dilakukan oleh pihak Peuyeum Abbas Sawargi.

\section{Sumber Daya Utama (Key Resources)}

Menurut Osterwalder dan Pigneur (2012), bahwa elemen ini menggambarkan aset-aset terpenting yang diperlukan agar sebuah model bisnis dapat berfungsi. Sumber daya utama yang terdapat pada Peuyeum Abbas Sawargi diantaranya sebagai berikut:

\section{a. Fisik (Physical)}

Sumber daya fisik yang dimiliki 


\section{MODEL BISNIS OLAHAN SINGKONG PADA USAHA PEUYEUM ABBAS SAWARGI \\ KECAMATAN CIMENYAN KABUPATEN BANDUNG \\ Dewi Rengganis, Gema Wibawa Mukti, Yosini Deliana, Dhany Esperanza}

oleh Peuyeum Abbas Sawargi diantaranya yaitu bangunan kecil sebagai tempat produksi, gudang dan tempat packing. Untuk peralatan produksi yang digunakan yaitu seperti timbangan manual, pisau, carangka, karung, panci besar, besek. Sedangkan untuk mendistribusikan barang, pihak Peuyeum Abbas Sawargi menggunakan mobil pick up.

\section{b. Manusia (Human)}

Manusia merupakan aset yang sangat penting dalam model bisnis, karena setiap bisnis memerlukan sumberdaya manusia. Saat ini, sumber daya manusia yang dimiliki oleh Peuyeum Abbas Sawargi berjumlah 12 orang dengan tugas dan tanggung jawab yang berbeda. Dalam usaha Peuyeum Abbas Sawargi ini terdiri atas 3 orang yang mengelola dengan peranan yang berbeda seperti bagian produksi, transportasi dan administrasi, pengelola dari peuyeum Abbas Sawargi ini merupakan anak dan mantu dari Bapak Abbas. Kemudian terdapat 5 orang yang membuat tape singkong dan 4 orang yang menyediakan singkong. Tidak ada ketentuan yang khusus untuk dapat bekerja di Peuyeum Abbas Sawargi ini, pihak Abbas Sawargi hanya membutuhkan orang yang ingin bekerja.
Sebagian besar pegawai Peuyeum Abbas Sawargi ini merupakan warga di daerah tersebut yang tidak memiliki pekerjaan, sehingga dengan adanya agroindustri ini dapat membantu warga dalam mendapatkan penghasilan.

Peuyeum Abbas Sawargi ini memproduksi tape singkong setiap hari, hal tersebut dikarnakan banyaknya pesanan yang harus dipenuhi, meski demikian para pekerja tidak memiliki jam kerja yang pasti, mereka bekerja apabila telah mendapatkan perintah dari Bapak Abbas selaku pemilik. Beliau akan memerintah pegawainya ketika singkong telah tersedia. Apabila jumlah tape singkong yang diproduksi lebih banyak maka, pekerja pun akan bekerja lebih lama, sehingga jam pulang pun tidak dapat dipastikan dan berbeda-beda di setiap harinya. Begitu juga untuk pegawai yang bertugas dalam menyediakan singkong. Mereka tidak memiliki jam kerja yang pasti dan termasuk ke dalam pegawai harian.

Terdapat pekerja tambahan yang membantu usaha Peuyeum Abbas Sawargi ini yaitu pekerja yang membantu dalam proses produksi peuyeum seperti membantu dalam proses pengupasan singkong. Pekerja tambahan ini jumlahnya tidak menentu dan bersifat 
sukarela tanpa diberikan upah. Para pekerja ini biasanya merupakan pengembala kambing, kerbau dan sapi, dimana mereka dapat membawa kulit luar dari singkong yang telah mereka kupas untuk ternaknya secara gratis. Sehingga dapat saling menguntungkan satu sama lain.

\section{c. Finansial (Financial)}

Sumberdaya finansial yaitu seperti uang tunai, kredit, kebutuhan-kebutuhan lain untuk memenuhi kebutuhan sumberdaya perusahaan. Finansial sebagai modal awal didirikannya usaha Peuyeum ini oleh Bapak Abbas yang merupakan modal pribadi, dimana Bapak Abbas menggunakan tabungannya sebesar Rp 3.000.000,00.- sebagai modal awal, namum seiring dengan bertambahnya pesanan dan membutuhkan tambahan pekerja untuk memenuhi pesanan tersebut maka, Bapak Abbas melakukan pinjaman ke bank. Selain untuk memenuhi kebutuhan produksi, pinjaman yang diajukan oleh Bapak Abbas digunakan untuk memodifikasi kemasan peuyeum yang tadinya hanya menggunakan carangka kecil hingga sekarang menggunakan besek dan membuat label pada kemasannya sehingga konsumen dapat membedakan antara peuyeun yang diproduksi oleh
Abbas Sawargi dengan peuyeum lainnya.

\section{Aktivitas Kunci (Key Activities)}

Key activities yang dilakukan Peuyeum Abbas Sawargi termasuk ke dalam kategori operasi produksi, karena aktivitas-aktivitas utama pada Peuyeum Abbas Sawargi terdiri atas pengadaan singkong sebagai bahan baku utama dalam pembuatan peuyeum ini, pengadaan ragi sebagai bahan campuran yang membantu dalam proses fermentasi, pengolahan dalam proses produksi, penyaluran produk jadi atau jasa kepada konsumen, dan administrasi.

Aktivitas produksi pada Peuyeum Abbas Sawargi ini dimulai dari mencari dan mengumpulkan singkong dari berbagai wilayah. Hal tersebut dilakukan pihak industri agar permintaan pasar dapat terpenuhi maka, bahan baku pun harus terus diperhatikan terutama bahan poko utama dalam pembuatan peuyeum ini yaitu singkong. Untuk mendapatkan singkong Bapak Een selaku pengelola mencari atau melakukan hubungan dengan pengumpul singkong di daerah setempat dan di daerah lain Seperti Sukabumi, Subang, Padalarang. Dengan adanya pasokan singkong yang banyak, maka usaha rumahan ini dapat terus berproduksi dan dapat memenuhi setiap 


\section{MODEL BISNIS OLAHAN SINGKONG PADA USAHA PEUYEUM ABBAS SAWARGI \\ KECAMATAN CIMENYAN KABUPATEN BANDUNG \\ Dewi Rengganis, Gema Wibawa Mukti, Yosini Deliana, Dhany Esperanza}

permintaan pasar. Jenis singkong yang digunakan yaitu singkong mangu dan mentega sebagai bahan baku pembuat peuyeum. Keuda jenis singkong ini sudah dipilih oleh Peuyeum Abbas Sawargi sejak pertama kali memproduksi, jenis ini dipilih karena rasanya yang legit dan akan menghasilkan peuyeum yang kenyal serta memiliki warna yang menarik untuk dipasarkan.

Dalam proses pembuatan peuyeum, Agroindustri Peuyeum Abbas Sawargi ini membutuhkan beberapa bahan baku penunjang, yaitu air dan ragi. Air yang digunakan berasal dari air bersih yang mengalir di daerah Kampung Babakan Cimenyan. Ragi yang digunakan proses fermentasi ini diperoleh dari pemasok yang akan mengirim ragi sebulan sekali. Apabila semua bahan sudah tersedia maka proses produksi pun dapat dijalankan.

Aktivitas pemasaran Peuyeum Abbas Sawargi dilakukan di sekitar Kabupaten dan Kota Bandung. Peuyeum Abbas Sawargi ini dipasarkan dengan cara memasok beberapa toko oleh-oleh khas Bandung dan toko kue Kartika Sari. Selain dipasarkan dengan memasok Peuyeum Abbas Sawargi ini dapat dibeli secara langsung di tempat produksi yang berlokasi di Desa Cimenyan, Kecamatan
Cimenyan, Kabupaten Bandung.

Aktivitas distribusi yang dilakukan oleh Peuyeum Abbas Sawargi yaitu mendistribusikan produknya dengan mengandalkan mobil pick up untuk mengantarkan pesanan ke toko oleh-oleh khas Bandung dan toko kue Kartika Sari. Proses pengiriman dilakuakn sesuai dengan perjanjian dan sesuai dengan pesanan konsumen. Adanya jasa antar atau delivery dapat memudahkan konsumen untuk mendapatkan peuyeum Abbas ini, setiap konsumen yang telah memesan peuyeum tersebut akan diantar ke tempat konsumen yang memesan. Dalam mendistribusikan produk Peuyeum Abbas Sawargi ini dilakukan secara langsung dan tidak langsung, dimana jika secara langsung, konsumen melakukan pembelian langsung ke tempat produksi, sedangkan distribusi secara tidak langsung dengan melalui penjualan di toko oleh-oleh khas Bandung dan toko kue Kartika Sari yang merupakan mitra dari peuyeum Abbas Sawarg ini. Namun sebagian besar konsumen melakukan pembelian Peuyeum ini dilakukan pada toko-toko yang telah dipasok oleh pihak Abbas Sawargi.

Aktivitas administrasi meliputi pembukuan dan pencatatan segala macam 
transaksi selama berjalannya usaha. Kegiatan pencatatan dan pembukuan dilakukan setiap kali memproduksi peuyeum dan masih secara manual atau tulis tangan dalam buku jurnal sehingga tidak dapat melakukan back up data apabila buku tersebut hilang. Walaupun pencatatan selalu rutin dilakukan setiap kali melakukan produksi, akan tetapi pencatatan tersebut masih belum rinci sehingga akan sulit untuk melacak kesalahan.

\section{Kemitraan Partnership)}

Utama

(Key

Peuyeum Abbas Sawargi melakukan kemitraan dengan beberapa petani singkong yang berada di sekitar Cimenyan dan petani singkong yang berada di Sukabumi, Subang dan Padalarang. Hal tersebut dilakukan untuk dapat memenuhi permintaan pasar sehingga bahan baku utama dalam memproduksi peuyeum ini pun akan selalu terpenihi. Dalam memenuhi kebutuhan bahan pokok usaha peuyeum ini memiliki beberapa proses yang yarus dilakukan, berikut merupakan alur dari pembelian singkong yang dilakukan oleh pihak Peuyeum Abbas Sawargi.

Adanya mitra ini sangat membantu pihak industri Peuyeum Abbas Sawargi, salah satu alasan adanya mitra dengan petani singkong di daerah dan tidak hanya mengandalkan singkong yang berada di daerah Cimenyan saja yaitu karena dengan melihat ketersediaan singkong di daerah Cimenyan tidak stabil dikarenakan banyaknya pembuat peuyeum sehingga para produsen saling bersaing untuk mendapatkan singkong dan melihat permintaan pasar yang cukup tinggi maka Peuyeum Abbas Sawargi membutuhkan singkong yang lebih banyak sehingga pihak Peuyeum Abbas Sawargi lebih memilih untuk melakukam mitra dengan petani singkong.

Selain bermitra dengan petani singkong, Peuyeum Abbas Sawargi ini bermitra dengan pemasok ragi. Ragi tersebut akan dipasok sebulan sekali, yang didatangkan dari Indramayu. Peuyeum Abbas Sawargi melakukan mitra dengan pengumpul kayu bakar yang berada di daerah Cimenyan. Adanya mita dengan pengumpul kayu ini yaitu untuk memasok kayu sebagai bahan bakar yang digunakan oleh pihak Peuyeum Abbas Sawargi dalam melakukan produksi. Kayu tersebut akan dipasok sebulan sekali.

Peuyeum Abbas Sawargi melakukan kemitraan dengan beberapa toko oleh-oleh khas Bandung dan toko kue Kartika Sari. Toko oleh-oleh yang 


\section{MODEL BISNIS OLAHAN SINGKONG PADA USAHA PEUYEUM ABBAS SAWARGI \\ KECAMATAN CIMENYAN KABUPATEN BANDUNG \\ Dewi Rengganis, Gema Wibawa Mukti, Yosini Deliana, Dhany Esperanza}

biasa dipasok oleh Peuyeum Abbas

Sawargi ini adalah toko oleh-oleh khas

Bandung yang berada di Jalan Pasteur, Jalan Buah Batu, Jalam Kopo, dan kios di rest area Tol Cipularang KM 62 dan $\mathrm{Km}$ 97. Adanya mitra dengan toko-toko tersebut dapat membantu pihak Peuyeum Abbas Sawargi dalam memasarkan produknya.

\section{Struktur Biaya (Cost Structure)}

Cost Structure pada Peuyeum Abbas Sawargi terbagi menjadi dua karakteristik, yaitu biaya tetap dan biaya variabel. Biaya tetap perusahaan meliputi upah pekerja, dan listrik. Sedangkan biaya variabel meliputi biaya keperluan produksi seperti biaya bahan baku (singkong), biaya untuk pembelian ragi, biaya untuk pembelian besek dan carangka sebagai kemasan peuyeum Abbas Sawargi ini, biaya pencetakan label, biaya bahan bakar kendaraan, dan biaya-biaya yang tak terduga.

\section{Model Bisnis Peuyeum Abbas Sawargi}

Berdasarkan penjelasan mengenai model bisnis olahan singkong menjadi peuyeum yang dijalankan oleh Abbas Sawargi di atas, didapatkan dengan melalui desain bisnis bercerita dan berpikir visual. Langkah selanjutnya yaitu menggambarkan model bisnis Peuyeum Abbas Sawargi secara singkat pada peta Business Model Canvas (BMC) dengan menggunakan sebuah kertas besar yang diibaratkan sebagai kanvas. Peta Model Bisnis Kanvas Business Model Canvas (BMC) tersebut diharapkan dapat mempermudah pengurus bisnis peuyeum dalam memahami model bisnis yang sedang dijalankannya serta dapat memahami pendapat konsumen mengenai produk Peuyeum Abbas Sawargi. 


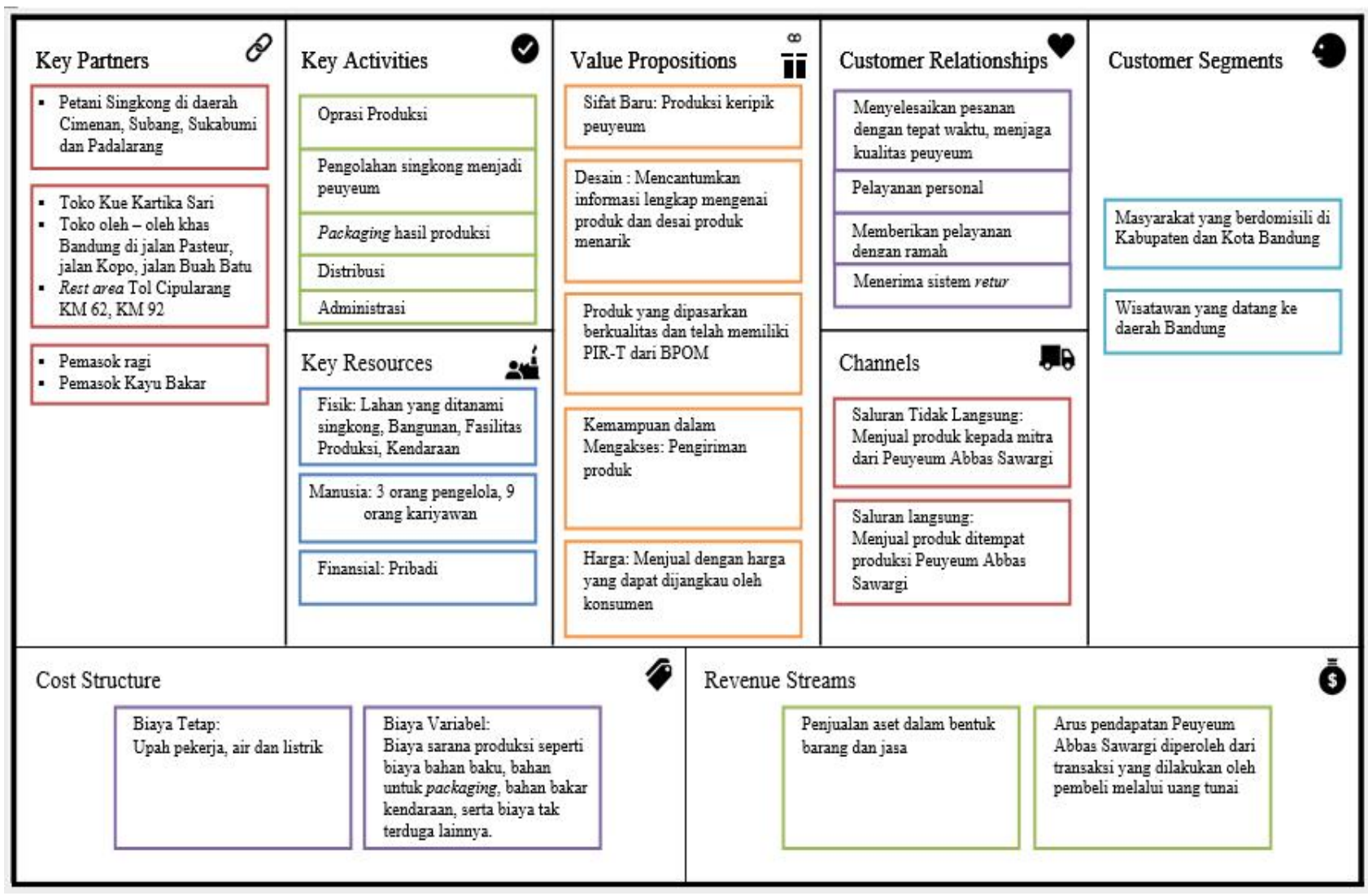

Gambar1. Model Bisnis Kanvas Pada Usaha Peuyeum Abbas Sawargi

\section{Kesimpulan}

Berdasarkan analisis Business

Model Canvas terdapat blok bangunan yang merupakan hal utama dalam terbentuknya usaha Peuyeum Abbas Sawargi ini yaitu dengan melihat Key Resources yang telah ada, seperti memanfaatkan singkong yang telah ditanam sehingga dapat dijadikan sebagai peluang bisnisnya. Singkong tersebut diolah menjadi peuyeum, hal ini dikarenakan proses pembuatan peuyeum cukup sederhana. Selain itu, pembuatan peuyeum ini telah dilakoni secara turun temurun. Terdapat beberapa kendala yang terdapat dalam usaha Peueyum Abbas
Sawargi yaitu pada blok Key Activity khususnya pada bagian promosi, pemasaran dan administrasi. Kurangnya kegiatan promosi yang dilakukan oleh Abbas Sawargi sehingga produk tersebut tidak terlalu banyak dikenal oleh masyarakat luas. Dalam pemasaran Peuyeum Abbas Sawargi ini belum tersebar luas di Kabupaten dan Kota Bandung. Administrasi pada usaha Peuyeum Abbas Sawargi ini masih dilakukan secara manual (tulis tangan) dalam buku tulis sehingga tidak dapat melakukan back up data apabila buku tersebut hilang, serta pencatatan tersebut masih belum rinci dan tidak memiliki 
format tetap sehingga pengurus akan sulit melacak apabila terjadi kesalahan.

\section{Saran}

Dari hasil penelitian yang telah dilakukan, terdapat beberapa saran untuk usaha Peuyeum Abbas Sawargi agar dapat lebih mengembangkan usahanya yaitu dengan menjaga dan menambah mitra untuk menyalurkan peuyeum yang telah diproduksi, sehingga dapat menjangkau konsumen akhir dengan lebih luas lagi. Untuk dapat memperbaiki blok Key Activity pada peuyeum Abbas Sawargi ini dapat melakukan kegiatan promosi menggunakan internet melalui media sosial seperti facebook, instagram, website ataupun media massa lainnya sehingga masyarakat di seluruh Indonesia dapat mengetahui produk dari Abbas Sawargi. Selain itu, dalam administrasi Peuyeum Abbas Sawargi dapat menggunakan sistem komputer dalam melakukan pencatatan setiap aktivitasnya
Mulai dari produksi sampai penjualannya, hal tersebut disarankan agar data dapat tersimpan dengan baik dan dapat meminimalisir risiko hilangnya data.

\section{DAFTAR PUSTAKA}

FAO. 2016. Statistical Databbase of Food Balance Sheet. FAOSTAT.

Kementan RI. 2014. Renstra Kementerian Pertanian Pertanian Tahun 2015-2019.

Osterwalder A \& Pigneur Yves. 2010. Business Model Generation. ISBN: 978-0470-87641-1.

Osterwalder, Alexander dan Yves Pigneur. 2012. Business Model Generation. PT Elex Media Komputindo: Jakarta.

Pusat Data dan Sistem Informasi Pertanian. 2013. Analisis PDB Sektor Pertanian Tahun 2013. Pusat Data dan Sistem Informasi Pertanian. Jakarta.

Pusat Data dan Sistem Informasi Pertanian. 2015. Analisis PDB Sektor Pertanian Tahun 2015. Pusat Data dan Sistem Informasi Pertanian. Jakarta. 